\title{
Study of fetomaternal outcome in cases of premature rupture of membrane at tertiary care rural institute of Western Uttar Pradesh, India
}

\author{
Jigyasa Singh, Vaibhav Kanti*, Vandana Verma
}

Department of Obstetrics and Gynecology, UPUMS, SAIFAI, Etawah, Uttar Pradesh, India

Received: 09 September 2019

Revised: 27 November 2019

Accepted: 02 December 2019

\author{
*Correspondence: \\ Dr. Vaibhav Kanti, \\ E-mail: vaibkanti13@gmail.com
}

Copyright: (c) the author(s), publisher and licensee Medip Academy. This is an open-access article distributed under the terms of the Creative Commons Attribution Non-Commercial License, which permits unrestricted non-commercial use, distribution, and reproduction in any medium, provided the original work is properly cited.

\begin{abstract}
Background: Premature rupture of membranes (PROM) is the rupture of the fetal membranes before the onset of labor. Preterm PROM complicates approximately 3 percent of pregnancies and leads to one third of preterm births. It increases the risk of prematurity and leads to a number of other perinatal and neonatal complications.

Methods: This was a prospective study carried out at the department of obstetrics and gynaecology, UPUMS, Saifai from April 2018 to September 2018 (6 months study). Patients with Spontaneous rupture of membranes any time beyond $28^{\text {th }}$ week of pregnancy, but before the onset of labour. Patients with following conditions were excluded from the study- meconium stain liquor, cord prolapse, antepartum haemorrhage, active infection at other sites, active liver disease.

Results: A total of 103 cases of premature rupture of membrane (PROM) were recorded from April 2018 to September 2019 among 1523 admitted pregnant patients. Most of the patients $56(54.36 \%)$ were delivered by caesarean section $(\mathrm{C} / \mathrm{S})$. Previous $\mathrm{C} / \mathrm{S}$, oligohydramnios, fetal distress, chorioamnionitis were the common indications for doing C/S. Forty-seven (45.63\%) patients were delivered vaginally.

Conclusions: Most of the affected women belongs to $20-24$ years of age $(53.39 \%)$. Term PROM was more in comparison to PPROM and most of them were multigravidae. Cesarean section rate was high. Most common complication was of subclinical urogenital infection $(51.02 \%)$.
\end{abstract}

Keywords: Chorioamnionitis, Fetal distress, Neonatal complications, Oligohydramnios, Prematurity, Preterm PROM

\section{INTRODUCTION}

Premature rupture of membranes (PROM) is the rupture of the fetal membranes before the onset of labor. ${ }^{1}$ This occurs near term in most cases, but when membrane rupture occurs before 37 weeks gestation, it is known as preterm PROM. Preterm PROM complicates approximately 3 percent of pregnancies and leads to one third of preterm births. It increases the risk of prematurity and leads to a number of other perinatal and neonatal complications, including a 1 to 2 percent risk of fetal death. ${ }^{1}$ One of the most common complications of preterm PROM is early delivery. The latent period, which is the time from membrane rupture until delivery, generally is inversely proportional to the gestational age at which PROM occurs. When preterm PROM occurs, surviving neonates may develop sequelae such as malpresentation, cord compression, oligohydramnios, necrotising enterocolitis, neurologic impairment, intraventricular hemorrhage, and respiratory distress syndrome.

Preterm PROM is associated with numerous risk factors. ${ }^{2}$ Black patient are at increased risk compared with white 
patient, lower socioeconomic status, are smokers, have a history of sexually transmitted infections, have had a previous preterm delivery, have vaginal bleeding, or have uterine distension (e.g., polyhydramnios, multifetal pregnancy). Procedures that may result in preterm PROM include cerclage and amniocentesis. Choriodecidual infection or inflammation may cause preterm PROM. A decrease in the collagen content of the membranes has been suggested to predispose patients to preterm PROM.

The diagnosis of PROM requires a thorough history, physical examination, and selected laboratory studies. Patients often report a sudden gush of fluid with continued leakage. Physicians should ask whether the patient is contracting, bleeding vaginally, has had intercourse recently, or has a fever.

\section{METHODS}

This was a prospective study where patients entering labour room and diagnosed having PROM were enrolled. It was carried out at the department of obstetrics and gynaecology, UPUMS, Saifai from April 2018 to September 2018. After formulation of aim of the study, a clinical data sheet was made for recording all informations of the pregnant women. After history taking, duration of gestational age was estimated from 1st day of last menstrual period, previous antenatal records, clinical examination and also previous ultrasonography reports.

\section{Inclusion criteria}

- Patients with spontaneous rupture of membranes any time beyond $28^{\text {th }}$ week of pregnancy, but before the onset of labour.

\section{Exclusion criteria}

- Meconium stain liquor

- Cord prolapses

- Antepartum haemorrhage

- Active infection at other sites, active liver disease.

Patients with chief complaints of leaking per vaginum were thoroughly examined. A detailed clinical history regarding age, religion, parity, address, education, socio economic status was taken. History of genital infection, previous pregnancy outcome and time of rupture of membrane and any intervention before admission, history of vaginal examination done outside the hospital were recorded.

In this study leaking was diagnosed by a per speculum examination. Patient was asked to evacuate the bladder and to take lithotomy position. Sims double blade speculum was introduced along with anterior vaginal wall retractor. Patient was asked to cough and presence or absence of leaking was noted.
Diagnosis of PROM was confirmed from history of gush of fluid coming from the vagina, demonstration of amniotic fluid leakage from the cervix by a sterile speculum examination $(\mathrm{P} / \mathrm{S})$ or pooling of amniotic fluid in posterior vaginal fornix and observation of oligohydramnios through USG.

During P/S examination, a high vaginal and endocervical swab was taken from all the patients and sent for culture and sensitivity, a blood sample for leukocyte count and urine for routine examination and culture sensitivity was sent. E.coli was most common pathogen.

Plan of management of patients with PROM was decided according to the condition of the patient, duration of gestational age, duration of membrane rupture, associated any complicating factors, maternal and fetal condition and also neonatal intensive care facility. Prophylactic antibiotic was given to reduce maternal and neonatal infective morbidity and to delay delivery. If the membranes had been ruptured for more than 18 hours, injection ampicillin $2 \mathrm{gm}$ IV every 6-hourly given to help reduce Group B streptococcus infection in the neonate. Betamethasone was given to the mother to improve fetal lung maturity if duration of pregnancy was less than 34 weeks.

Conservative management was given when gestational age less than 37 weeks. But PROM with more than 37 weeks, a vaginal examination $(\mathrm{P} / \mathrm{V})$ was done to assess Bishop's score. After initial evaluation, $\mathrm{P} / \mathrm{V}$ was restricted to minimum and a progress of labour was monitored from nature of uterine contraction and descent of fetal head. Cesarean section was performed when PROM was complicated with other factors.

After delivery all the babies were assessed by Apgar score and sent to neonatology dept if any complicating factor was present.

\section{RESULTS}

A total of 103 cases of premature rupture of membrane (PROM) were recorded from April 2018 to September 2019 among 1523 admitted pregnant patients.

Table 1: Age distribution of patients with PROM $(n=103)$.

\begin{tabular}{|lll|}
\hline Age group & Number of patients & Percentage (\%) \\
\hline$<25$ & 59 & $57.19 \%$ \\
\hline $25-30$ & 31 & $30.09 \%$ \\
\hline$>30$ & 13 & $12.6 \%$ \\
\hline
\end{tabular}

The hospital incidence of PROM was found to be $6.76 \%$. Among them, 55 (53.39\%) patients were admitted at term (>37 weeks) and $48(46.60 \%)$ patients came before 37 completed weeks of gestation. 
Table 1 shows that most of the affected women belonged to below 25 years of age $(57.19 \%)$. Thirty-one women belong to age group of 25-30 years (30.09\%) and only 13 $(12.6 \%)$ women belong to age more than 30 years. In this study $43 \%$ were primigravidae and $57 \%$ were multigravidae.

Table 2: Complications of PROM $(n=49)$.

\begin{tabular}{|lll|}
\hline Indication & $\begin{array}{l}\text { No. of } \\
\text { patients }\end{array}$ & $\begin{array}{l}\text { Percentage } \\
(\%)\end{array}$ \\
\hline $\begin{array}{l}\text { Pregnancy with subclinical } \\
\text { urogenital infection }\end{array}$ & 25 & $51.02 \%$ \\
\hline Oligohydramnios & 14 & $28.57 \%$ \\
\hline Chorioamnionitis & 6 & $12.24 \%$ \\
\hline $\begin{array}{l}\text { Pregnancy with medical } \\
\text { disease }\end{array}$ & 4 & $8.16 \%$ \\
\hline
\end{tabular}

Forty-nine (47.5\%) patients presented with different complications with PROM. (Table 2) shows that most common complication was of subclinical urogenital infection $(51.02 \%)$ whereas 14 women had oligohydramnios $(28.57 \%)$ and 6 women $(12.24 \%)$ women presented with chorioamnionitis. Four women $(8.16 \%)$ had pregnancy with medical diseases.

Table 3: Delivery outcome.

\begin{tabular}{|l|ll|}
\hline Type of delivery & $\begin{array}{l}\text { Number of } \\
\text { babies }\end{array}$ & $\begin{array}{l}\text { Percentage } \\
(\%)\end{array}$ \\
\hline LSCS & 56 & $54.36 \%$ \\
\hline Vaginal delivery & 47 & $45.63 \%$ \\
\hline
\end{tabular}

Note: Fifty-six mothers underwent caesarean section and 47 had normal delivery.

Table 3 shows most of the patients $56(54.36 \%)$ were delivered by caesarean section(C/S). Previous caesarean section, oligohydramnios, fetal distress, chorioamnionitis were the common indications for doing caesarean section. Forty-seven (45.63\%) patients were delivered vaginally.

Table 4: Fetal birth weight.

\begin{tabular}{|lll|}
\hline Fetal weight $(\mathrm{kg})$ & $\begin{array}{l}\text { Number of } \\
\text { babies }\end{array}$ & $\begin{array}{l}\text { Percentage } \\
(\%)\end{array}$ \\
\hline$<1.5$ & 31 & $30.09 \%$ \\
\hline $1.6-2$ & 15 & $14.56 \%$ \\
\hline $2.1-3.0$ & 52 & $50.48 \%$ \\
\hline$>3$ & 5 & $4.78 \%$ \\
\hline
\end{tabular}

Table 4 shows that most of the babies $52(50.48 \%)$ had birth weight between $2.1-3.0 \mathrm{~kg}, 31(30.09 \%)$ babies had birth weight less than $1.5 \mathrm{~kg}$ and 15 (14.56\%) babies were born between 1.6 to $2 \mathrm{~kg}$ body weight. Five babies $(4.78 \%)$ had birth weight of more than $3 \mathrm{~kg}$.

Table 5 shows that immediately after birth $78(75.72 \%)$ babies were born with Apgar score > 7, 19 babies (18.44) had Apgar score between 4-6, 4 babies (3.88\%) had

Table 5: Apgar score for babies $(n=103)$.

\begin{tabular}{|lll|}
\hline Apgar score & Number of babies & Percentage (\%) \\
\hline$>7$ & 78 & $75.72 \%$ \\
\hline $4-6$ & 19 & $18.44 \%$ \\
\hline$<3$ & 4 & $3.88 \%$ \\
\hline 0 & 2 & $1.94 \%$ \\
\hline
\end{tabular}

Note: Seventy-eight babies had Apgar Score above 7 whereas 25 had below 7 .

Apgar score of less than three. Two babies (1.94\%) had zero Apgar score at birth. There was no maternal death but perinatal death was $5(4.8 \%)$.

Table 6: Relation of mode of delivery with duration of PROM.

\begin{tabular}{|lllll|}
\hline PROM to delivery interval & Vaginal & Percentage & LSCS & Percentage \\
\hline$<12$ hours & 4 & $3.8 \%$ & 10 & $9.7 \%$ \\
\hline $12-24$ hours & 7 & $6.79 \%$ & 6 & $5.82 \%$ \\
\hline $24-48$ hours & 12 & $11.65 \%$ & 15 & $14.56 \%$ \\
\hline $2-7$ days & 19 & $18.44 \%$ & 8 & $16.50 \%$ \\
\hline$>7$ days & 5 & $4.85 \%$ & $\mathbf{5 6}$ & $7.76 \%$ \\
\hline Total & $\mathbf{4 7}$ & & \\
\hline
\end{tabular}

Table 6 shows that most of the patients $36(34.95 \%)$ had delivery interval of 2 to 7 days in which 19 had vaginal delivery and 17 underwent caesarean section. Twentyseven $(26.21 \%)$ patients had delivery interval of $24-48$ hours in which 12 had vaginal delivery ad 15 underwent caesarean section. Fourteen patients $(13.5 \%)$ had delivery interval of less than 12 hours in which 4 had vaginal delivery and 10 underwent caesarean section and thirteen patients $(12.61 \%)$ had duration between 12-24 hours in which 7 had vaginal delivery and 6 underwent caesarean section. Thirteen patients $(12.61 \%)$ also had delivery interval of more than 7 days in which 5 had vaginal delivery and 8 patients underwent for caesarean section.

\section{DISCUSSION}

PROM is an important cause of preterm labour and delivery of a low birth weight baby resulting in high 
perinatal mortality and morbidity. ${ }^{3}$ In our country, true incidence of PROM is very difficult to ascertain because more than $80 \%$ deliveries occur at home. This study conducted at UPUMS, shows the incidence of PROM in hospital was $6.76 \%$.

A study undertaken at Dhaka Medical College Hospital $(\mathrm{DMCH})$ in 1995 showed the incidence of PROM to be $8.12 \%$ and it was $9.05 \% .4,5$ Another study at Rangpur Medical College Hospital reported an incidence of 9.04\%. ${ }^{6}$ The incidence at Indian studies from Mumbai reported by Bhalerao and Desai and Bhide and showed an incidence of PROM between 7 and $12 \%{ }^{7}$

Daftary and Desai correlated the incidence of PROM with the gestational maturity and reported that PROM before the onset of true labour occurred in $5-20 \%$ of all women in labour. ${ }^{8}$ Although there is some morbidity when PROM occurs in term pregnancies, the fundamental clinical problem is preterm PROM, a condition that occurs in $3 \%$ of all pregnancies and is responsible for approximately $30 \%$ of all preterm deliveries as reported by Arias and Tomich. ${ }^{9}$

During the study period, 55 (53.39\%) patients were admitted at term (>37 weeks) and 48 (46.60\%) patients came before 37 completed weeks of gestation. In this study, most of the affected patients belongs to 20-24 years of age which is similar to other studies. ${ }^{4-6}$

In many studies, high parity is one of the risk factors for increasing PROM. ${ }^{4-6}$ In present study, maximum women were multigravida (59\%) coming from low socioeconomic families. Low socio-economic status is an important risk factor for both PROM and preterm labour. Associated factors such as malnutrition, overexertion, poor hygiene, stress, recurrent genitourinary infections and anaemia considerably increase the risk. In a study by Begum, 50\% patients were in the group of low socioeconomic condition having no or irregular antenatal check-up which is almost similar to this study. ${ }^{6}$

Romero et al reported that infection is twice as frequent in PROM than in preterm labour with intact membranes. In another study by Romero et al, in term PROM the incidence of infection was approximately $20 \%$ and in PPROM it was $38.3 \% .^{10}$ Also, women with PPROM and labour at the time of admission had a greater incidence of chorioamnionitis than women with PPROM admitted without labour. ${ }^{10}$ Associated maternal medical and obstetrical complications had highly significant impact on PROM.

In the study by Begum, $77.3 \%$ of PROM patients were admitted with different complications. Among them $8.5 \%$ patients presented with chorioamnionitis. About 54\% patients had maternal complications and $11 \%$ patients had clinical evidence of chorioamnionitis.6 Another study by Miller et al and Johnson et al observed prevalence of microbial invasion of amniotic cavity with PROM as $30 \% .^{11}$

In present study, high vaginal swab culture was positive in $25.8 \%$ patients. E.coli was most common pathogen. The microorganisms isolated from amniotic fluid cultures (Peptostreptococcus, Bacteroides, Fusobacterium, Lactobacillus, Ureaplasma urealyticum) are similar to those normally found in the vagina, strongly suggesting that the source of infection is bacteria normally present in the vagina or the cervix. The mechanism of ascending infection is not clear. ${ }^{2}$ Hein et al observed that changes in the antibacterial properties of cervical mucus may also play an important role in facilitating ascending infection. ${ }^{12}$ The importance of factors that theoretically may increase the possibility of ascending infection such as sexual intercourse, pelvic digital examinations during pregnancy and history of prior cervical dilatation for abortion or $\mathrm{D}$ and $\mathrm{C}$ has been disproved by clinical investigations. On the other hand, colonization of the lower genital tract by Chlamydia, Neisseria gonorrhoeae, group B Streptococcus, Tricomonas, E.coli and bacteroid species has been shown to increase the risk of PROM. ${ }^{2}$

Begum shows that only $32 \%$ patients were delivered by C/S. Puerperal sepsis (5.6\%) and wound infections $(21.25 \%)$ were common puerperal complications which are similar to other studies. ${ }^{4-6}$ A reduction in incidence of puerperal sepsis is due to proper use of antibiotics and timely termination of pregnancy. ${ }^{6}$

During our study period, most of the babies $39(37.86 \%)$ had birth weight between 2.1-2.5 kg, 31 (30.09\%) babies had birth weight less than $1.5 \mathrm{~kg}$ and $15(14.56 \%)$ babies were born between 1.6 to $2 \mathrm{~kg}$ body weight. Several studies have concluded that hyaline membrane disease is the greatest threat to the newborn when PROM occurs before term. The data from Mercer show that at all gestational age the risk of respiratory distress is greater than the risk of infection. At 24 weeks $100 \%$ of the newborns develop respiratory distress syndrome, at 32 weeks $25 \%$ and at 34 weeks close to $10 \%$. The risk of sepsis at these gestational ages was 40, 32, 4.5 and 3\%, respectively. ${ }^{13}$

\section{CONCLUSION}

Most of the affected women belongs to 20-24 years of age $(53.39 \%)$. In this study $43 \%$ were primigravidae and $57 \%$ were multigravidae. Term PROM was more in comparison to PPROM and most of them were multigravidae. Caesarean section rate was high. Most common complication was of subclinical urogenital infection $(51.02 \%)$. In developing countries like India, incidence of perinatal morbidities is still higher especially in resource poor setting.

Proper aseptic precautions during labour can help to decrease incidence of neonatal sepsis. More and more institutions worldwide now accept the early induction in 
cases of PROM to improve perinatal outcome. Although early diagnosis and proper management can be helpful in decreasing prenatal morbidities in cases of PROM, more randomised controlled trials involving larger sample size is required to draw further conclusions.

\section{ACKNOWLEDGMENTS}

Authors would like to thank Dr. Vaibhav Kanti for her exemplary guidance, valuable feedback and constant encouragement throughout the duration of the research work. Her valuable suggestions were of immense help throughout our work. Author would also like to thank Dr. Vandana Verma for her help and guidance in this research work.

Funding: No funding sources Conflict of interest: None declared Ethical approval: Not required

\section{REFERENCES}

1. Krishna UR, Shah MH. Prelabour Rupture of Membranes, Obstetrics and Gynecology for Postgraduates, edited by S.S. Ratnam, K. Bhasker Rao and S. Arulkumaran, 2nd edition; 1999;1:96108.

2. Arias F, Daftary SN, Bhide AG. Premature Rupture of Membrane, Practical Guide to High-Risk Pregnancy and Delivery, A South Asian Perspective, $3^{\text {rd }}$ edition; 2008:240-261.

3. Dutta DC. Prelabour Rupture of the Membranes, Text Book of Obstetrics, $6^{\text {th }}$ edition; 2006:317-320.

4. Tasnim S. Clinical profile and outcome of pregnancy in premature rupture of membrane: a study in Dhaka Medical College Hospital. Dissertation; Bangladesh College of Physicians and Surgeons; 1995.

5. Begum A. Maternal and fetal outcome of premature rupture of membrane: one-year study in Dhaka Medical College Hospital. Dissertation; Bangladesh College of Physicians and Surgeons; 2001.
6. Begum N. Epidemiology of Premature Rupture of Membrane and Management in Rangpur Medical College Hospital. Dissertation; Bangladesh College of Physicians and Surgeons; 2004.

7. Bhalerao S, Desai A. Premature rupture of membranes. Jn: Saraiya UB, Rao KB, Chatterjee A, eds. Principles and Practice of Obstetrics and Gynecology ( $2^{\text {nd }}$ edn). An FOGSI Publication. New Delhi: Jaypee Brothers; 2003:125.

8. Daftary SN, Desai SV. Preterm labour and premature rupture of membranes. In: Daftary SN, Desai SV, eds. Selected Topics in Obstetrics and Gynaecology ( $2^{\text {nd }}$ edn). New Delhi: BI Publications; 2006:128.

9. Arias F, Tomich PH. Etiology and outcome of low birth weight and preterm infants. Obstet Gynecol. 1982;60:277-81.

10. Romero R, Yoon BH, Mazor M, Gomez R, Gonzalez $\mathrm{R}$, Diamond MP, et al. A comparative study of the diagnostic performance of amniotic fluid glucose, white cell count, interleukin-6 and Gram stain in the detection of microbial invasion in patients with preterm premature rupture of the membranes. Am J Obstet Gynecol. 1993;169:839-51.

11. Johnson JWC, Daikoku NH, Niebyl JR, Johnson JT, Khouzami VA, Witter FR Premature rupture of membranes and prolonged latency. Obstet Gynecol. 1981;57:547-56.

12. Hein M, Helmig RB, Schønheyder HC, Ganz T, Uldbjerg N. An in vitro study of antibacterial properties of the cervical mucous plug in pregnancy. Am J Obstet Gynecol. 2001:185.

13. Pressman EK, Cavanaugh JL, Woods JR. Physical properties of the chrioamnion throughout gestation. Am J Obstet Gynecol. 2002;187;672-5.

Cite this article as: Singh J, Kanti V, Verma V.

Study of fetomaternal outcome in cases of premature rupture of membrane at tertiary care rural institute of Western Uttar Pradesh, India. Int J Reprod Contracept Obstet Gynecol 2020;9:77-81. 